\title{
Rainbow country surgery reggae seeds smile
}

\author{
F. M. Riegler
}

Published online: 26 November 2013

(C) Springer-Verlag Wien 2013

\section{Dear readers,}

Let us start with a smile. Today, we frequently experience meeting people who lack a friendly smile. Great, that you stopped by to come in for those lines. Take your time. Did you just swallow your old years' globus sensation saliva? Feel free to sit down, relax, and follow me to the start of an important sound. It seems you had a very hard day. Be happy and satisfied. Tuff gong surgery. Very special cases. Hard-rock dissection. Caval naval valve blood spearing activities. Ready for heart clubbing. You did a great job for the master entertainer of your institution; there is always one above and ahead of you within this type of institution. Do you wish to have a drink? Twinkle water? Lemon joke? Hour of ginger? Guinea pig pasta? Gin chromo stain? Bladder on the rocks? Taste your rhythmic mood. When did you stop to smoke, chill, and make love? Who killed your motivation? Liver loves fatty leisure taste of pure cure.

Slowness opens the eye and gives birth to a new happy smiling lovely day. Beauty enters the atmosphere. Coziness flavors the mind. Colors are the wings of your thoughts. Fly permanently high. Ideas follow the leaves of the tree (Fig. 1). Dread locks are the branches to the I (Fig. 2). What makes the being to be, to come into existence? Perception? Thought? You? Can there be being without perception of existence? With time, the leaves cover the soil of their ground surrounding the root of the tree like a shadow follows the matter within the radiation of light (Figs. 1 and 2). Grass eats the light and cuts it into black pieces. Spirit uncovers a soul. Open your mind and eyes for the horizon above (Fig. 3). Far above the limits of any system that you may be aware of. Saints are air-

F. M. Riegler $(\bowtie)$

Manometry Lab \& Department of Surgery, Medical University Vienna, Waehringer Guertel 18-20, 1090 Vienna, Austria

e-mail: franz.riegler@meduniwien.ac.at planes within a carrier. Mission deserves attention, even in Syria and Egypt. Do not be afraid. NSA is watching you, so they say and sniff snow then. There is no proof. Maybe reggae counts different, because of a myth. TV presents a continuous YouTube Hollywood entertainment radiation show. Rockers seed the burdens. Penny market feeds them all.

Striking event: thus came into thought the emotion to think. Get yourself together and find some time to examine your world, while snow covers most of the northern hemisphere. Winter not only names a blue jeans-wearing tattoo-lined singing Johnny with an electric homemade blues guitar (145).

Critical thinkers do not follow the sound of the magic flute, the smell of the designer cake, and the sweet trumpet taste of the candida cardia. Get ready to twist your chronicle. Step out of the clinic, close the door behind you, take the full blow of the entire winds, and stand in front of the worldwide cosmic blue-yellow soundless ocean light. Behind you, there feels history. Angles are nurses with qualities. Sickle cell phones to blood stream: give me planets. Future is the expectation. Foetor ex oracle. Giving signs. Face the waving hot water shine in your moving face mingling from far-away pastures turning the ancient legacies into pyramid bag published future assumptions (Sri Lanka Tea Test; $p<0.001$ ). The now counts the cow brilliant diamond coin visions into the evidence-based model emotions of your half-moon minded nails. It seems we are stuck, somehow. Version captures existence. Foster frames. There is a shallow rainbow horizon teaching you plentiful matrix of stars. Take five Beethoven, Mahler, and Brubeck and listen to the verily tunes of the laughing saxophone trombone bra bras rainbow ahead.

Listen to the rainbow: "I am one of the very last opener with the colorful beams of swinging wing. Spectrum of sounds, colors, and tastes, rivers, mountains, skies, and seas remember my name. From far-away distant times, 


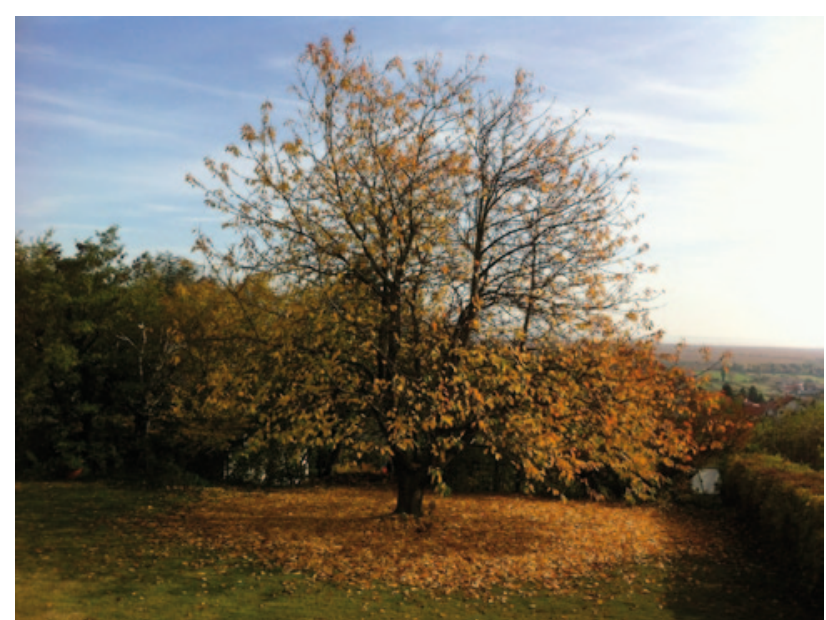

Fig. 1 The branches are the dreadlocks to the I, behind which opens the blue of the sky to the hidden cosmic harmony. Planet biopsy obtained using iPhone

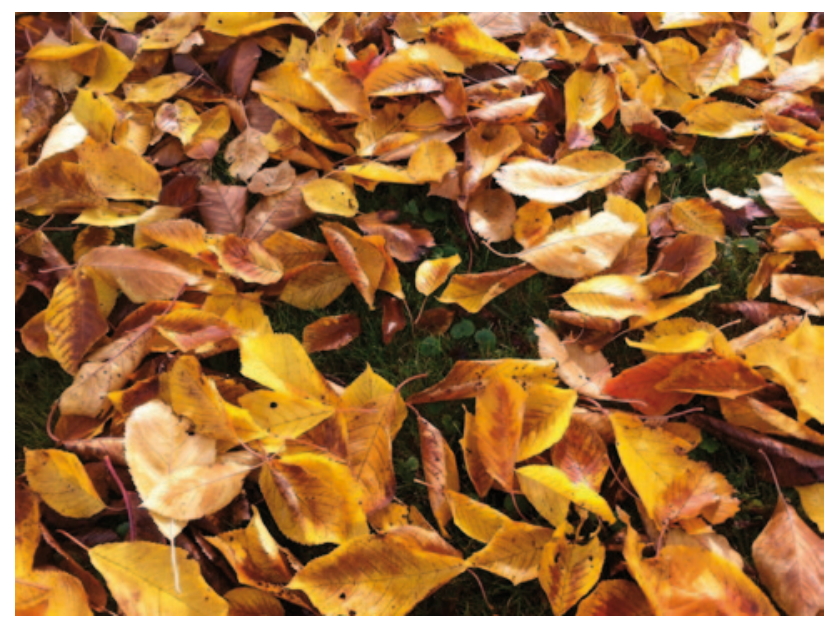

Fig. 2 Like leaves, ideas may descend to cover the ground and shadow of the soil to which the hidden roots nourish the tree of knowledge. The image mirrors the circle of perception, as outlined in the text. Optical biopsy obtained from our planet in Purbach/Neusiedlersee/Austria, using iPhone technology

I pass myself over to you to open a verily wisdom to the academic surgeon behind the muting mask of mystery. It only needs rain, light, and you to watch me to keep me alive. Would I exist if you would not see me, recognize me, perceive me, nourish me with adoration? You may not be able to cut me out into pieces, although you are a brilliant on-call surgeon. Who aims to cut light serves a star."

Here and now, there comes the time for the roots returner basic academic surgeon. Unmask the masks of the monastery of oncology and functional life qualitydeserving activities. The rainbow mingled: "Listen to my colors mutation: our time is now. Ray bone la monde bring lane face the automatic multiplication of systems within systems giving birth to deprivation, anxiety, and loss of link to the very roots of our existence: my cal modern life lacks link to the soil of being, you did the spirit

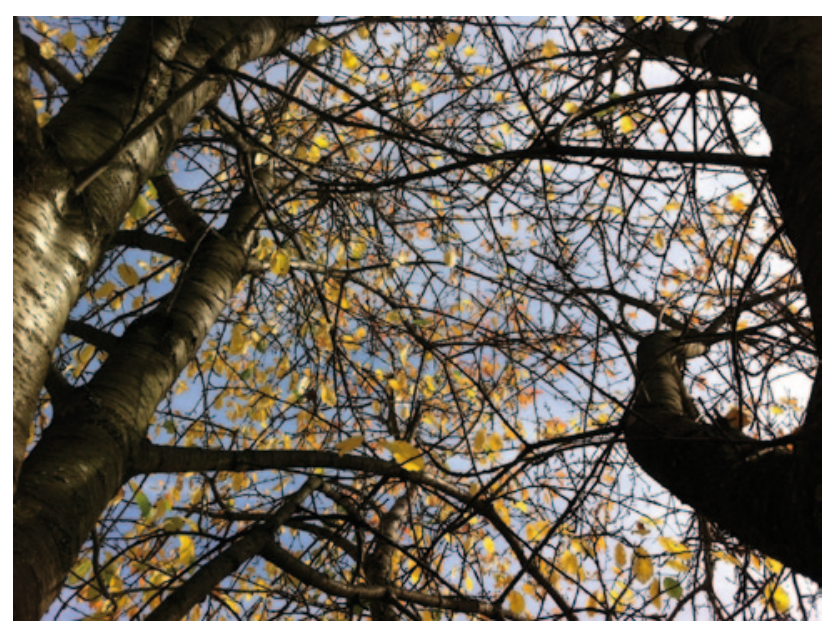

Fig. 3 Dome-like over-out-branching network pointing out to the above behind the sky. The image mirrors how physis contains it all, irrespective of the model-based dimensions

of waters revealing the running polyposis pearl covering the knowledge of the well. As the number of systems and subsystems increases, the insecurity demands a rectum in spiritu reactor creator reaction of those captured within the network of those permanently and ubiquitously lying, hate-, greed-, and envy-spitting spiders."

The oncoplastic sinking planet takes it all to some point. Reduction restores as black matter becomes invisible. Momentum periodical. And here comes the rooter, the tune connected to the soil water and spirits of the universe, revealing the hidden secrets of the everlasting pusher: the more you get, the higher you grow, the more important you wish, the deeper you shall fall back into the essence. Archaic bubbling be lonian linguistic lingerie: reasoning and being is the same. Today, the system divides and multiplies with enormous hyperplastic, polygenetic speed, perception beams ahead of space, emotions are swallowed with a self-estimated energy drink to push it down to the hidden world of forgotten needs, and mutations cut out happiness. Cold white pale-skin body outside, inside tears rush down the walls of the intestine, diarrhea cries out loud, blood pressure rises, adenomas commence to grow to sing out and are not understood, because the multiple subsystems impair the great open vision. Leaders and led, who wishes to escape the possible fall of the academy should reside and step out now. Leave the tree (Fig. 2) to prosper the vision (Fig. 3). Long and tuff pieces of art and organization require longer intermissions. Every year needs a winter. Step out of the concert hall and take a deep breath of air, fresh up yourself with the rinsing joy of a glass of water and the green fury of an apple providing neutralization of the gastric acid and offering an important pulse of energy for your body. Rethink your estimates, if you wish to serve systems that overdo, exploit emotions and dreams, in direct hunt for more high speed directly flying into the very end of the wall. They all follow the global Google greed eater.

Physis takes it all; like the flower, it opens to hide and closes to reveal, as it shares when the world kisses your 
eyes for the last time before your long dive. Whose river contains the leaf, whose heaven harbors the shadow below, folded unfolded goes the being beat timeless, spaceless, just so. And here starts what all poetry is about. Techne forms gods, closes their eyes, and sends them to sleep. Hands are made to take off the mask from our face. Unmasked we start to stare behind the blue sky. Physis knows, techne is not allowed to know. This is why "god" had to die in favor of the birth of "being." This is why Beckett had to make us wait for "god." The train never came. We are touched by the perception of the tune beyond the mask. Once upon a time, there was a tear, clear and wide, deep and open, and out of this tear was made your world, and so it is all you perceive: the very essence of the tear. And the ocean? The ocean forms the tear of the earth. And when the earth cries, it gives birth to her children: the moon, the stars, the milky way, and your dreams. And when men and women cry, there cries the earth. And when people, animals, plants, countries laugh, there laughs the earth. The world finds love within a tear and space for a laughter.

Oncology mask unhidden. Leaves fell, sheet the green, hide the seen into the perspective of history. Who made it see fall except you? Can you be sure? Who stands and awaits silence? Never stop to ask: why you?

And here in the clinic, the majority hides behind the masks to cover their faces, to cheat, bluff, and be someone else. Did they ever wish to know who they are?

Those who have the power and strength to take off the heavy mask and step out quietly become loud without any sound and find the fresh waters of the well, the nourishing waves of the air, live a life again and SMILE AGAIN. At this point, the rainbow retracts into the wonderful dome glory wide uprising blue and continues to shine as remembrance of an optical taste. SMILE from ABOVE. May rainbows smell. Rivers fly. Mountains laugh. Clouds hide. Pass changes. Politics justify fecal pride. Election is selection. Being answers in the form of perceptions. Did you ever consider the symbolism of a mirror from this background of reasoning? Who is this face? Brush your soul, connector, and try the best to be you.

Sincerely, Martin Riegler

\section{Conflict of interest}

The author declares that there is no conflict of interest. 